\title{
KUALITAS FUNGSI SEKSUAL IBU POSTPARTUM DENGAN JAHITAN PERINEUM DIUKUR MENGGUNAKAN FEMALE SEXUAL FUNCTION INDEX
}

\author{
Ester Ratnaningsih \\ Prodi Pendidikan Profesi Bidan Universitas Respati Yogyakarta \\ Jl. Raya Tajem KM 1.5 Maguwoharjo, Depok, Kenayan, Wedomartani, Kecamaran Ngemplak, Kabupaten Sleman, Daerah \\ Istimewa Yogyakarta. 08156731268 \\ Email: esteratna@gmail.com
}

\begin{abstract}
ABSTRAK
Aktivitas seksual wanita berubah pada berbagai tahap kehidupan, salah satunya karena proses persalinan. Masalah seksual wanita setelah melahirkan adalah trauma perineum saat melahirkan seperti ruptur perineum. Tujuan penelitian ini adalah untuk mendapatkan gambaran indeks fungsi seksual ibu postpartum dengan jahitan perineum di Rumah Sakit Panti Wilasa Citarum Semarang tahun 2019. Desain penelitian ini adalah study deskritif, dengan besar sampel 45 orang, pengambilan sampel dilakukan dengan teknik aksidental sampling. Disfungsi seksual dinilai dengan kuesioner FSFI.Hasil penelitian menunjukkan mayoritas responden berumur 20-35 tahun sebanyak 40 responden (88,9\%), mayoritas ibu multipara sebanyak 28 responden (62,2\%), mayoritas responden berpendidikan SMA sebanyak 30 responden (66,7\%), dan mayoritas responden menyusui sebanyak 41 responden (91,1\%) dan mayoritas responden melakukan hubungan seksual 3 bulan setelah bersalin sebanyak 24 responden $(53,3 \%)$, Skor indeks fungsi seksual ibu postpartum dengan jahitan perineum dengan rentang 4 - 34,2. Kejadian disfungsi seksual pada ibu nifas dengan jahitan perineum sebanyak 86,7\%.
\end{abstract}

Kata kunci : disfungsi seksual; postpartum; jahitan perineum

\begin{abstract}
Women's sexual activity changes at various stages of life, one of which is childbirth processes. Sexual problem among women after giving birth is perineal trauma during childbirth to perineal rupture. This study wasaimed to obtain an overview of the sexual function index among postpartum women with perineal sutureat Panti Wilasa Citarum Hospital of Semarang in 2019. The design of this study was a descriptive study, with a number of samples of 45 people, sampling was conducted by accidental sampling technique. Sexual dysfunction assessed by the FSFI questionnaires. The results showed that the majority of respondents aged 20-35 years of 40 respondents (88.9\%), the majority of respondents were multipara women of 28 respondents (62.2\%), the majority of respondents had a high school education of 30 respondents (66.7\%), and the majority of respondents performed breast-feeding of 41 respondents (91.1\%) and the majority of respondents had sexual intercourse 3 months after giving birth of 24 respondents (53.3\%). The sexual function index score among postpartum women with perineal suture was in the range of 4 - 34.2. Conclusion the incidence of sexual dysfunction among postpartum women with perineal suture was $86.7 \%$.
\end{abstract}

Keywords: perineal suture; postpartum; sexual dysfunction 


\section{LATAR BELAKANG}

Kesehatan seksual merupakan salah satu pilar penyokong dalam status "sehat" seseorang. Menurut World Health Organization (WHO), kesehatan seksual didefinisikan sebagai integrasi aspek somatik, emosional, intelektual dan sosial dalam berbagai cara yang memperkaya dan menambah kualitas kepribadian, komunikasi dan cinta. (KammererDoak D, 2008). Fungsi seksual merupakan komponen yang penting dalam kehidupan perempuan dan memiliki peran penting dalam keharmonisan dalam rumah tangga. Aktivitas seksual wanita berubah pada berbagai tahap kehidupan dan dipengaruhi oleh banyak faktor, salah satunya karena kehamilan dan persalinan.

Masa pasca persalinan membawa banyak perubahan dalam kehidupan seorang perempuan. Perubahan fisik dan tanggung jawab pasca kelahiran bayi seringkali mempengaruhi kondisi emosional dan pada akhirnya berpengaruh pada kehidupan seharihari termasuk dalam masalah seksual (Cunningham FG, 2010). Gangguan seksual yang terjadi pada wanita pasca persalinan umumnya diakibatkan oleh disfungsi otot dasar panggul (Pelvic Floor Muscle). Otot dasar panggul yang sehat ada pada wanita yang sehat dan dapat dijadikan untuk memuaskan stimulasi genital dan pencapaian orgasme. Kelemahan otot dasar panggul memberikan stimulasi gairah yang tidak adekuat, sehingga menghambat potensi orgasme. Menurut hasil penelitian sekitar $25-50 \%$ dari wanita dengan gangguan otot dasar panggul memiliki gangguan fungsi seksual (Mokhtar et al, 2013).

Menurut Admin (2011, dalam Asri, 2013) mengatakan bahwa 20\% wanita yang baru melahirkan memiliki keinginan berhubungan seksual pada tiga bulan pasca melahirkan, sedangkan 21\% lainnya mengaku tidak memiliki keinginan untuk bercinta. Beberapa faktor yang berhubungan dengan penurunan fungsi seksual postpartum antara lain menyusui, persalinan pervaginam, persalinan secara operatif, trauma perineum, robekan vagina dan episiotomi. Beberapa penelitian memperlihatkan bahwa penurunan hubungan seksual terjadi pada post natal namun performa kembali ke sebelum kehamilan dalam waktu 1 tahun setelah persalinan (El- Begway AF, 2010). Masalah seksual pada ibu setelah melahirkan dapat terjadi dispareunia dan keluhan seksual, termasuk penurunan libido, kesulitan orgasme, dan lubrikasi vagina berkurang (Cunningham FG, 2010).

Sebagian besar ibu bersalin dengan episiotomi dan jahitan perineum mengalami trauma saat akan melakukan hubungan seksual kembali, sementara faktanya $74 \%$ memang masih merasakan masih nyeri saat berhubungan seksual, kendati jahitan perineum telah kering (Wulandari, 2011). Sejalan dengan itu, Fodstad et Al. (2016) mendapatkan bahwa adanya luka perineum berhubungan signifikan dengan keterlambatan dimulainya kembali hubungan seksual dalam dua dan tiga bulan postpartum (Fodstad et al. 2016).

Salah satu pertanyaan yang paling sering diajukan pada akhir persiapan kelahiran adalah berapa lama setelah melahirkan dapat melakukan kembali hubungan seksual yang normal (Wulandari, 2011). Aktivitas seksual pasca bersalin yang aman adalah berhubungan kembali setelah enam minggu dihitung sejak kelahiran bayi (Thamrin, 2010). Wanita dengan persalinan normal tanpa jahitan perineum, setelah selesai masa nifas dapat kembali menikmati hubungan seksual, namun jika terdapat luka jahitan perineum, membutuhkan waktu lebih lama lagi. Biasanya dalam waktu 4 bulan luka episiotomi benar-benar sembuh dan hubungan seksual bisa dilakukan kembali tanpa adanya nyeri (Sari, 2014).

Pengukuran kualitas perilaku seksual dapat dilakukan dengan Indeks Fungsi Seksual Perempuan (Female Sexual Function Index, FSFI) yang dirancang untuk penilaian uji klinis fungsi seksual wanita. FSFI sudah di validasi berdasarkan DSM IV (Diagnostic and Statistical Manual of Mental Disorders, Fourth Edition). FSFI adalah keseluruhan nilai atau skor diskriminan dari item - item yang dihimpun ke dalam 6 domain berikut : (1) desire (dorongan), (2) arousal (rangsangan), (3) lubrication (lubrikasi), (4) orgasm (orgasme), (5) satisfation (kepuasan), (6) pain ( nyeri). Setiap domain 
terdiri atas beberapa item yang bisa didiskriminasikan menurut persepsi wanita bersangkutan. (Kamerrer D,2008).

Umumnya sesudah melahirkan banyak wanita memerlukan waktu yang lebih lama daripada sebelumnya untuk mencapai orgasme. Kelambatan bangkitnya gairah seks ini sering berhubungan dengan perubahan tingkat hormonal dan kelelahan. Hubungan seksual sesudah melahirkan terasa berbeda dengan sebelum hamil, sebab tubuh wanita mengalami perubahan anatomis yang sesungguhnya sehingga mempengaruhi mekanisme maupun kenikmatan dalam hubungan seks bahkan tekanan sedikit pada dasar vagina dengan jari saja, sakitnya terasa berminggu-minggu. (Musbikin, 2007; h. 328)

Dari hasil penelitian terdahulu oleh Sri Karyati (2016) di Desa Jurang Kabupaten Kudus didapatkan bahwa ibu yang mengalami jahitan perineum grade I sebagian besar mengalami ansietas (kecemasan) dalam berhubungan seksual ringan yaitu 12 orang $(85,7 \%)$, sedangkan ibu yang mengalami jahitan perineum grade 2 sebagian besar mengalami ansietas berat yaitu 16 orang $(76,2 \%)$. Penelitian lain oleh Darmayasa (2012) di di Rumah Sakit Sanglah Denpasar didapatkan hasil rata-rata ibu nifas mulai hubungan seksual pada kedua kelompok ibu dengan episotomi dan post sectio sesarea adalah tiga bulan pasca melahirkan, dengan Indeks Fungsi Seksual Perempuan kedua kelompok didapatkan disfungsi seksual masing-masing 18,60\% pada pasca episiotomi, dan 2,33\% pada pasca seksio sesarea.

Berdasarkan studi pendahuluan pada Ibu nifas yang berkunjung ke poliklinik kebidanan dan kandungan Rumah Sakit Panti Wilasa Citarum Semarang dengan menggunakan kuesioner terhadap ibu postpartum sebanyak 10 orang, didapatkan hasil sebanyak 7 ibu mempunyai masalah takut untuk mulai melakukan hubungan seksual dan 3 ibu merasa keinginan berhubungan seksual menurun setelah melahirkan. Berdasarkan waktu mulainya hubungan seksual setelah melahirkan sebanyak 3 ibu mulai melakukan hubungan seksual pada bulan kedua, 5 orang ibu mulai melakukan hubungan seksual pada bulan ketiga, dan ada 2 orang ibu belum melakukan hubungan seksual setelah melahirkan. Alasan ibu belum melakukan hubungan seksual setelah melahirkan karena ibu belum mengetahui kapan waktu yang tepat boleh melakukan hubungan seksual setelah melahirkan

Disfungsi seksual seringkali tidak disadari baik oleh pasien maupun klinisi, namun ternyata membawa dampak bagi kehidupan berumah tangga. Di lapangan terlihat masih banyak ibu nifas dengan jahitan perineum yang memiliki masalah dan ketakutan dalam memulai hubungan seksual setelah melahirkan. Hal ini akan berdampak dalam hubungan suami istri, sehingga berdasarkan latar belakang tersebut maka penulis tertarik melakukan penelitiaan tentang " Kualitas Fungsi Seksual Ibu Postpartum dengan Jahitan Perineum diukur dengan Menggunakan Female Sexual Function Index (FSFI). Tujuan penelitian untuk mengetahui fungsi seksual ibu postpartum dengan jahitan perineum di Rumah Sakit Panti Wilasa Citarum Semarang..

\section{METODE}

Jenis penelitian ini adalah penelitian observasional deskriptif (Sugiono, 2010). Tempat penelitian dilakukan di Poli Kebidanan dan Kandungan Rumah Sakit Panti Wilasa Citarum Semarang dengan dengan subyek penelitian ibu nifas dengan jahitan perineum dinilai menggunakan kuesioner Female Sexual Function Index (FSFI). Penelitian dilakukan pada bulan Mei 2019.

Populasi terjangkau pada penelitian ini adalah ibu nifas dengan jahitan perineum yang datang berkunjung ke poliklinik kebidanan dan kandungan Rumah Sakit Panti Wilasa Citarum Semarang antara bulan Januari sampai Februari 2019 sebesar 180 orang. Sampel penelitian ibu nifas yang melahirkan spontan dengan jahitan perineum yang memenuhi kriteria inklusi. Kriteria inklusi ibu nifas normal dengan jahitan perineum tiga - empat bulan sebelumnya, bersedia mengikuti penelitian. 
Kriteria eksklusi adalah ibu yang sudah tidak memiliki pasangan seksual selama tiga empat bulan pasca persalinan, ibu nifas yang mempunyai potensi hambatan untuk mendapatkan informasi yang dapat dipercaya seperti pasien skizofrenia, cacat mental, atau dalam keadaan sakit berat.

Teknik pengambilan sampel dengan aksidental sampling. Perhitungan sampel dengan rumus Slovin dengan tingkat kepercayaan 0,01 didapatkan sampel sebesar 45 orang. (Nursalam ,2008)

\section{HASIL}

\section{Karakteristik Subyek Penelitian}

Pada penelitian dengan 45 sampel ibu postpartum spontan dengan jahitan perineum dengan karakteristik subyek penelitian berdasarkan usia ibu, riwayat paritas, riwayat pendidikan dan riwayat menyusui.

\section{Tabel 1 Distribusi Responden berdasar Karakteristik responden}

\begin{tabular}{lcc}
\hline Karakteristik & Frekuensi & Persentase (\%) \\
\hline Usia Ibu & & \\
$<20$ tahun & 3 & 6,7 \\
$20-35$ tahun & 40 & 88,9 \\
$>35$ tahun & 2 & 4,4 \\
Paritas & & \\
Primipara & 15 & 33,3 \\
Multipara & 28 & 62,2 \\
Grandemulti & 2 & 4,4 \\
Pendidikan & & \\
SMP & 5 & 11,1 \\
SMA & 30 & 66,7 \\
PT & 10 & 22,2 \\
Menyusui & & \\
Ya & 41 & 91,1 \\
Tidak & 4 & 8,9 \\
Mulai aktivitas seksual setelah melahirkan & \\
2 bulan & 18 & 40 \\
3 bulan & 24 & 53,3 \\
4 bulan & 3 & 6,7 \\
\hline Total & 45 & 100,0 \\
\hline
\end{tabular}

Berdasarkan tabel 1 diatas, subyek penelitian menunjukkan jumlah sampel ibu dengan pasca persalinan spontan dengan jahitan perineum pada lebih banyak pada usia 20-35 tahun sebesar 40 responden $(88,9 \%)$. Distribusi sampel berdasarkan paritas menunjukkan kelompok terbanyak pada pasien pasca persalinan spontan adalah pada multipara yaitu 28 sampel $(62,2 \%)$, selanjutnya primipara yaitu 15 sampel $(33,3 \%)$, sedangkan 2 sampel lainnya $(4,4 \%)$ pada kelompok grandemultigravida.

Distibusi karakteristik sampel berdasarkan pendidikan pada pasien pasca persalinan spontan dengan jahitan perineum terbanyak dalam kelompok SMA, yaitu 30 sampel (66,7\%), kemudian pada distribusi karakteristik yaitu riwayat menyusui hampir semua ibu menyusui bayinya selama nifas sebesar 41 orang $(91,1 \%)$.

Gambaran Kualitas Fungsi Seksual Ibu Postpartum dengan Jahitan Perineum Berdasarkan Skor FSFI (Female Sexual Function Index = Indeks Fungsi Seksual Perempuan)

Gambaran umum (deskripsi) fungsi seksual ibu nifas dengan jahitan perineum berdasarkan Skor FSFI (Female Sexual Function Index = Indeks Fungsi Seksual Perempuan) dapat dilihat pada tabel 2 .

\section{Tabel 2 Distribusi Responden berdasarkan} Total Skor Rerata Domain FSFI

\begin{tabular}{lcc}
\hline $\begin{array}{l}\text { Jumlah Skor } \\
\text { rerata domain } \\
\text { FSFI }\end{array}$ & Frekuensi & Persentase (\%) \\
\hline$<10$ & 12 & 26,7 \\
$10-19,9$ & 17 & 37,8 \\
$20-26,5$ & 10 & 22,2 \\
$\geq 26,5$ & 6 & 13,3 \\
\hline Total & $\mathbf{4 5}$ & $\mathbf{1 0 0}$ \\
\hline
\end{tabular}

Berdasarkan total skor FSFI (Female Sexual Function Index = Indeks Fungsi Seksual Perempuan) tersebut untuk menilai kejadian disfungsi seksual pada ibu postpartum dengan jahitan perineum, yang dapat dilihat pada tabel 3. 
Tabel 3 Distribusi Frekuensi Responden Menurut Status Disfungsi Seksual

\begin{tabular}{lcc}
\hline $\begin{array}{l}\text { Jumlah Skor rerata } \\
\text { domain FSFI }\end{array}$ & N & $\%$ \\
\hline $\begin{array}{l}\text { Disfungsi Seksual } \\
\text { Normal }\end{array}$ & 39 & 86,7 \\
\hline Total & 6 & 13,3 \\
\hline
\end{tabular}

Berdasarkan jumlah skor rerata domain FSFI (Female Sexual Function Index = Indeks Fungsi Seksual Perempuan) pada tabel 2 diatas, terdapat 6 responden ( $13,3 \%$ ) yang memiliki skor rata- rata lebih dari 26,5. Ini artinya terdapat 6 orang responden yang memiliki fungsi seksual normal. Sedangkan pada tabel 3 memperlihatkan sebanyak 39 orang $(86,7 \%)$ responden memiliki gangguan disfungsi seksual dengan total skor FSFI di bawah cut off 26,55. Distribusi responden berdasarkan ke -6 domain penilaian Skor FSFI (Female Sexual Function Index = Indeks Fungsi Seksual Perempuan) dapat dilihat pada tabel 4.

Tabel 4 Distribusi Responden berdasar Domain Skor FSFI (Female Sexual Function Index = Indeks Fungsi Seksual Perempuan)

\begin{tabular}{lcc}
\hline Domain & Mean & Standar Deviasi \\
\hline Dorongan & 3,50 & 1,37 \\
Bangkitan & 3,39 & 1,36 \\
Lubrikasi & 2,89 & 1,85 \\
Orgasme & 2,61 & 2,01 \\
Kepuasan & 2,72 & 2,12 \\
Nyeri & 2,23 & 2,46 \\
\hline
\end{tabular}

Berdasarkan tabel 4 menunjukkan bahwa sebagian besar interpretasi klinik dari Female Sexual Function Index (FSFI) yang terdiri dari 6 (enam) struktur yang dapat diukur yaitu dorongan, bangkitan, lubrikasi, orgasme, kepuasan dan nyeri. Tabel 4 menunjukkan bahwa rerata terendah ibu nifas postpartum dengan jahitan perineum dalam fungsi seksual adalah point nyeri dalam melakukan hubungan suami istri dengan rerata 2,23. Sedangkan hasil interprestasi fungsi seksual tertinggi pada dorongan atau keinginan untuk melakukan aktivitas seksual dengan rerata 3,50.

\section{Tabel 5. Distribusi Frekuensi Gangguan Seksual Pada Ibu Postpartum Dengan Jahitan Perineum berdasar Domain Skor FSFI (Female Sexual Function Index = Indeks Fungsi Seksual Perempuan)}

\begin{tabular}{ccc}
\hline Domain & Frekuensi & $\begin{array}{l}\text { Persentase } \\
\text { (\%) }\end{array}$ \\
\hline $\begin{array}{c}\text { Dorongan } \\
\text { Normal }\end{array}$ & 10 & 22,2 \\
$\quad$ Rendah & 35 & 77,8 \\
Bangkitan & & \\
$\quad$ Normal & 7 & 15,5 \\
$\quad$ Rendah & 38 & 84,5 \\
Lubrikasi & & \\
$\quad$ Normal & 8 & 17,7 \\
$\quad$ Rendah & 37 & 82,3 \\
Orgasme & & \\
$\quad$ Normal & 5 & 11,1 \\
$\quad$ Rendah & 40 & 88,9 \\
Kepuasan & & \\
$\quad$ Normal & 11 & 24,4 \\
$\quad$ Rendah & 34 & 75,6 \\
Nyeri & & \\
$\quad$ Normal & 13 & 28,9 \\
Rendah & 32 & 71,1 \\
\hline
\end{tabular}

Berdasarkan hasil penelitian pada tabel 5 memperlihatkan bahwa sebagian besar responden mengalami disfungsi seksual pada setiap domain fungsi seksual yaitu dorongan, bangkitan, lubrikasi, kepuasan, orgasme, kepuasan dan nyeri. Hasil penelitian ditemukan adanya gangguan seksual tertinggi berupa gangguan orgasme yakni sebanyak 40 ibu $(88,9 \%)$.

\section{PEMBAHASAN}

Hasil penelitian terhadap fungsi seksual ibu postpartum dengan jahitan perineum menunjukkan bahwa dari 45 responden sebanyak 39 responden (86,7\%) mengalami disfungsi seksual. Hasil penelitian ini diukur menggunakn skor indeks fungsi seksual dengan rentang skor 4 - 34,2. Disfungsi 
seksual pada wanita didefinisikan sebagai gangguan yang terjadi pada salah satu atau lebih dari keseluruhan siklus respons seksual normal yang berpengaruh terhadap aktivitas seksualnya. Penyebab disfungsi seksual setelah melahirkan salah satunya adalah cedera jalan lahir. Sampel penelitian ini adalah ibu postpartum dengan jahitan perineum dalam persalinan, karena adanya robekan perineum secara spontan ataupun episiotomi.

Berdasarkan hasil penelitian menunjukkan bahwa terdapat 6 responden (13,3\%) yang memiliki fungsi seksual normal, sedangkan 39 orang $(86,7 \%)$ responden memiliki gangguan disfungsi seksual dengan total skor FSFI di bawah cut off 26,55 . Hasil ini sesuai penelitan (Rathfisch, 2010) menunjukkan perempuan dengan ruptur perineum derajat II ternyata memiliki tingkat libido, orgasme, dan kepuasan seksual yang lebih rendah dan lebih banyak rasa sakit selama hubungan seksual dibandingkan perempuan dengan perineum yang intak. Demikian pula pada penelitian (Altuntuğ, K, 2017) di Turki dari 246 responden postpartum periode satu tahun, sebanyak 36,6 $\%$ mengalami dispareunia dalam hubungan seksual pertama setelah melahirkan dan 41,5 $\%$ mengalami dispareunia pada periode postpartum.

Disfungsi seksual pada responden penelitian ini mengakibatkan sejumlah 53,3\% responden melakukan hubungan seksual pertama kali pada 3 bulan periode pascasalin, sedangkan $40 \%$ melakukan hubungan seksual pertama kali pada 2 bulan pasca bersalin. Berdasarkan hasil wawancara, alasan ibu menunda hubungan seksual antara lain takut jahitan lepas, nyeri pada jahitan, capek mengurus anak.

Hasil Penelitian ini sejalan dengan penelitian Yusnia I di RSUD Panembahan Senopati Bantul Yogyakarta sejumlah 26,5\% subjek melakukan hubungan seksual pertama kali pada 8 minggu periode pascasalin, sedangkan $34,3 \%$ belum melakukan hubungan seksual.

Berdasarkan skor Female Sexual Function Index (FSFI) yang terdiri dari 6 (enam) domain yaitu dorongan, bangkitan, lubrikasi, orgasme, kepuasan dan nyeri, menunjukkan bahwa rerata terendah ibu nifas postpartum dengan jahitan perineum dalam fungsi seksual adalah point nyeri dalam melakukan hubungan suami istri dengan rerata 2,23. Nyeri saat berhubungan seksual (dispareunia) adalah nyeri saat melakukan hubungan seksual, baik disebabkan kelainan fisik maupun psikologis. Pada tabel 5 juga menunjukkan ibu nifas dengan jahitan perineum mengalami gangguan nyeri dalam berhubungan suami istri atau dispareunia sebanyak 71,1\%. Penelitian Maria Olva (2017) juga mendapatkan hasil sebanyak $34 \%$ responden dengan ruptura perineum karena episiotomi maupun ruptur spontan mengalami dispareunia.

Hasil penelitian pada tabel 5 ditemukan adanya gangguan seksual tertinggi berupa gangguan orgasme yakni sebanyak 40 ibu (88,9\%). Orgasme adalah puncak kenikmatan seksual ditandai dengan pelepasan ketegangan seksual dan kontraksi ritmik pada otot-otot perineal dan organ reproduktif pelvis. Pada wanita, orgasme ditandai oleh 3 sampai 15 kali kontraksi involunter pada sepertiga bagian bawah dan oleh kontraksi uterus yang kuat dan lama, berjalan dari fundus turun ke serviks. Kesulitan pencapaian orgasme juga didapatkan pada hasil penelitian Irwanto (2014) di Rumah Sakit dr Saiful Anwar Malang dimana kelahiran pervaginam paling terkait dengan relaksasi otot panggul dan episiotomi dapat memperburuk efek pencapaian orgasme pada wanita pasca melahirkan. Penelitian Leal, et al (2013) menyebutkan bahwa kemampuan untuk mencapai orgasme setelah melahirkan diperoleh dalam waktu enam minggu pasca bersalin.

Pada domain kepuasan seksual didapatkan sebanyak $75,6 \%$ ibu postpartum dengan jahitan perineum mengalami gangguan kepuasan seksual. Kepuasan seksual dideskripsikan sebagai kemampuan mencapai orgasme setiap kali melakukan hubungan seksual. Hal ini tercapai saat keadaan perangsangan maksimal. Ketika orgasme terganggu, maka kepuasan seksual kemungkinan besar kepuasan seksual tidak akan tercapai dengan baik. Hal ini sesuai 
dengan hasil penelitian Irwanto (2014) di Rumah Sakit dr Saiful Anwar Malang didapatkan bahwa ada penurunan tingkat kepuasan seksual pada ibu nifas dengan episiotomi mediolateral, namun tidak terdapat perbedaan kepuasan seksual antara ibu nifas episiotomi mediolateral dan seksio sesarea.

Pada domain lubrikasi didapatkan sebanyak $82,3 \%$ ibu postpartum dengan jahitan perineum mengalami gangguan lubrikasi. Lubrikasi merupakan proses sekresi mukus pada vagina yang dihasilkan oleh beberapa kelenjar vestibular diantaranya kelenjar bartholin yang terdapat diantara himen dan labia minora. Lubrikasi vagina dipengaruhi oleh: hasrat seksual yang dipengaruhi psikis, penggunaan obat-obatan atau larutan pencuci vagina, dehidrasi, menyusui, menopause. Menyusui merupakan salah satu penyebab kekeringan vagina, dispareunia dan penurunan libido. Hal ini karena berkaitan reaksi fisiologis hiperprolaktinemia setelah prose menyusui yang menyebabkan penurunan kadar estrogen, progesteron dan androgen. Penurunan estrogen ini berdampak terhadap penurunan lubrikasi. (Leal , et all, 2013)

Pada domain dorongan atau minat hubungan seksual didapatkan hasil sebanyak $77,8 \%$ ibu nifas dengan jahitan perineum mengalami gangguan dorongan atau minat dalam berhubungan seksual. Hal ini sejalan dengan hasil penelitian Jamileh Mlakoti , 2012 di Iran menemukan hampir semua wanita menyusui menderita disfungsi seksual dan skor FSFI terendah libido dan gairah seksual. Penurunan estrogen mempengaruhi wanita menyusui dan menyebabkan hilangnya libido, gairah, dan orgasme yang menyebabkan kekeringan pada vagina. Ini juga berkaitan dengan perilaku seksual berisiko menurunkan skor fungsi seksual. Beberapa faktor yang mempengaruhi seksualitas perempuan postpartum antara lain penurunan estrogen, kekeringan vagina, nyeri saat hubungan seksual dan kurangnya waktu dan energi karena kesulitan perawatan bayi, kelelahan, stres, dan kekhawatiran tentang kehamilan lagi. (Shirvani MA, 2010)

\section{KESIMPULAN DAN SARAN}

Pada penelitian ini telah dilakukan penilaian fungsi seksual ibu postpartum dengan jahitan perineum di Rumah Sakit Panti Wilasa Citarum Semarang dengan hasil : skor indeks fungsi seksual ibu postpartum dengan jahitan perineum dengan rentang $4-34,2$; kejadian disfungsi seksual pada ibu nifas dengan jahitan perineum sebanyak 39 responden $(86,7 \%)$ dan gangguan seksual tertinggi pada ibu nifas dengan jahitan perineum adalah gangguan orgasme yakni sebanyak 40 ibu $(88,9 \%)$. Berdasarkan hasil penelitian tentang disfungsi seksual pada ibu nifas dengan jahitan perineum maka dapat menjadi usulan untuk ditindak lanjuti bidan/ perawat agar pengkajian aspek seksualitas lebih fokus diberikan kepada klien di bagian obstetri ginekologi serta perlu adanya kebijakan lokal rumah sakit di Unit kebidanan dan poli nifas agar bidan/ perawat $m$ memberikan pendidikan kesehatan seksualitas masa nifas dalam upaya menyiapkan periode pasca melahirkan.

\section{REFERENSI}

Asri N. 2013. Hubungan Peran Petugas Kesehatan Dan Media Informasi Dengan Perilaku Seksual Pada Ibu Pasca Nifas Di Wilayah Kerja Puskesma Peukan Bada Kabupaten Aceh Besar. Laporan Tugas Akhir. Jurusan Kebidanan Sekolah Tinggi IImu KesehatanU'budiyah Banda Aceh

Altuntuğ, K., Ege, E., Kocoğlu, D., Akın, R., \& Demirören, N. 2017. Prevalence of dispareunia in women within postpartum one-year period and related factors. Journal of Human Sciences, 14(2), 16691673.

Cunningham FG, Leveno KJ, Bloom SL, Haut JC, Rouse DJ, Spong CY, editors. 2010. Williams Obstetrics .23rd ed Chapter 30: The Puerpurium. New York: McGrawHill. 695-710.

Darmayasa M. 2013. Perbedaan Fungsi Seksual Wanita Pasca Persalinan Pervaginam Dengan Episiotomi Dan 
Seksio Sesarea. E-Journal Obstetric \& Gynecology Udayana. Vol 1, No 2

El-Begway AF, Elshamy FF, Hanfy HM. 2010. The Effect of Pelvic Floor Exercise on Sexual Function after Vaginal Delivery. Med J. Cairo Univ; 78(2):27-31

Fodstad K., Staff A.C, Laine K. 2016. Sexual activity and dyspareunia the first year postpartum in relation to degree of perineal trauma. International Urogynecology Journal and Pelvic Floor Dysfunction 27(10), 1513-23

Irwanto, 2018. Perbedaan Disfungsi Sexual Wanita yang Melahirkan Secara Pervaginam dengan Episiotomi Media Lateral dan Seksio Sesarea. Journal of issues in Midwifery, Desember 2018Maret 2019, Vol 2.No.3.45-59

Jamileh M, Vahid Z, Ahdieh M, Azizeh F. 2013.Sexual Function in Breastfeeding Women in Family Health Centers of Tabriz, Iran, 2012. Journal of Caring Sciences. Jun 2(2).141-146

Kamerrer D, Rebecca G, MD Rogers. 2008. Female Sexual Functionand Dysfunction, Obstet Gynecol Clin N Am 35 ; p 169183

Leal et al. 2013. Masturbation Among Women: Associated Factors and Sexual Response in a Portuguese Community Sample. Journal of Sex \& Marital Therapy. 39:347-367.

Maria O, Sri Astuti, Maria M. 2017. Kejadian Dyspareunia pada Ruptur Perineum Jurnal Riset Kesehatan Poltekkes Depkes Bandung Feb. 2017.Vol 2(2), p. 22-26,.

Mokhtar, Mas Sahidayana., Fatimah Ibrahim., Nur Farahana Mohd Rozi., Juhaida Mohd Yusof., Siti Anom., Yen Ahmad, Su Khong,Siti Zawiah Omar. 2013. A quantitative approach to measure womens's sexual function using electromyography: A preliminary study of the kegel exercise. Medical Science Monitor. 19: 1159 - 1166
Musbikin I. 2007. Persiapan Menghadapi Persalinan. Yogyakarta : Mitra Pustaka. h.328.

Nursalam. 2008. Konsep dan Penerapan Metode Penelitian IImu Keperawatan, Ed. 2. Salemba Medika

Rathfisch G, Dikencik BK, Kizilkaya Beji N. 2010. Effects of Perineal Trauma On Postpartum Sexual Function. Journal of Advanced Nursing. Dec;66(12), 2640-9.

Sari, E. P. dan Rimandini, K. D. 2014. Asuhan Kebidanan Persalinan (Intranatal Care). Jakarta Timur: CV. Trans Info Media

Shirvani MA, Nesami MB, Bavand M. 2010. Maternal sexuality after child birth among Iranian women. Pak J Biol Sci . 2010;13(8):385-9.

Sri Karyati. Jahitan Perineum, Dukungan Suami, Ansietas Seksual Ibu Postpartum. The ${ }^{3 r d}$ Universty Research Colloquium 2016; 2016. 444-453

Sugiyono. 2010. Metode Penelitian Pendidikan Pendekatan Kuantitatif, kualitatif, dan R\&D. Bandung: Alfabeta

Thamrin, R. (2010). Hubungan Seks Pasca Melahirkan. Diambil 28 September, 2010, dari http://konsultasikesehatan.epajak.org

Wulandari, Setyo Retno. (2011). Asuhan Kebidanan Ibu Masa Nifas. Yogyakarta : Gosyen Publising.

Yusnia Irchami. Gangguan Hasrat Seksual Pada Wanita Pascasalin dan Hubungannya Dengan Cara Persalinan. Jurnal Kesehatan Reproduksi,Vol. 2(1).April $2015.29-33$ 